\title{
SCADA Office Building Implementation in the Context of an Aggregator
}

\author{
Omid Abrishambaf ${ }^{1}$, Pedro Faria ${ }^{1}$, Zita Vale ${ }^{1}$ \\ ${ }^{1}$ GECAD - Knowledge Engineering and Decision Support Research Centre, Polytechnic of Porto (IPP), Porto, \\ Portugal ombaf@isep.ipp.pt, pnf@isep.ipp.pt, zav@isep.ipp.pt
}

Abstract - This paper at first presents an aggregation model including optimization tools for optimal resource scheduling and aggregating, and then, it proposes a real implemented SCADA system in an office building for decision support techniques and participating in demand response events. The aggregator model controls and manages the consumption and generation of customers by establishing contract with them. The SCADA based office building presented in this paper is considered as a customer of proposed aggregation model. In the case study, a

distribution network with 21 buses, including 20 consumers and 26 distributed generations, is proposed for the aggregator network, and optimal resource scheduling of aggregator, and performance of implemented SCADA system for the office building, will be surveyed. The scientific contribution of this paper is to address from an optimization-based aggregator model to a SCADA based customer.

Index Terms - Aggregator, Demand response, Optimization problem, SCADA office building, Automation.

\section{INTRODUCTION}

The concept of Demand Response (DR) program is topic of a significant number of research works. It can be defined as modification of the electricity usage patterns in demand side for responding to the price variations, which is based on any technical or economic problems [1]. Electricity users are able to participate in incentive-based and price-based DR programs [2]. These kinds of management programs enable the grid operator to have flexibility on the consumption of network, in order to fully benefit from the local generation resources. Direct Load Control (DLC) and load shifting, are two effective DR tools for the network management entities [3].

On the other hand, if Distributed Generation (DG), especially renewable resources namely Photovoltaic (PV) and wind generation, are considered beside the DR programs, the grid operator can fully benefit from these concepts for optimal management of consumption and generation resources [4].

However, there are two barriers for typical electricity customers that make them incapable to participate in this kinds of management programs. At first, they should have an adequate amount of generation or consumption reduction to be able to participate in the wholesale markets [5], and then, they

should have automation infrastructures for managing the electricity consumption and generation [6]. To overcome the first barrier, a third-party entity is placed between the demand side and grid side to aggregate all small and medium scale resources and participate them in the market as a unique resource [7]. Curtailment Service Provider (CSP) [8], and Virtual Power Plants (VPP) [9] are two concepts that can play the role of aggregator in the network. For overcoming the second barrier, Supervisory Control and Data Acquisition (SCADA) systems enable the customers to have automatic control over the consumption and generation [10]. However, before the massive implementation of any business models, they should be well tested and surveyed for preventing future problems.

The main idea of this paper is divided into the two sections. The first part of the work focuses on an aggregation model for DG and DR resources including optimization tools for optimal resource scheduling and aggregating. Also, the cost minimizing of aggregator is considered in this model. The second section of the paper aims at the real implementation of SCADA system in an office building for decision making and participating in the DR events. This office building is considered as a player of the aggregation model developed in the first part of the paper, and its performance during DR events will be surveyed. In this system, several real controller components, such as distributed based Programmable Logic Controllers (PLCs), manage the consumption and generation of the building based on the optimal resource scheduling results of the aggregator.

There are several relevant works focused in this area. A profit-based aggregator model has been developed in [11] for residential DR in order to address the smart grid resource allocation problem. In [12], CSP is considered as a load aggregator in order to be applied in the Colombian day-ahead electricity markets. An aggregator model has been designed in [13] for thermostatically controlled loads aggregation in order to participate in DR programs. Reference [14] presents a resource scheduling model for feeding the electricity demand of commercial and office buildings. However, this paper provides an optimal aggregation model responsible for DR events and optimal resource scheduling, and then, it will focus on a real implemented SCADA model in an office building. The scientific contribution of this paper includes the whole perspective of an optimization-based aggregator model to a

single intelligent customer.

After this introductory section, the aggregator model is presented in Section II. The mathematical formulation for optimization problem will be demonstrated in Section III. Section IV shows the technical aspects of the implemented

SCADA system. A case study will be proposed in Section V, and its results are shown in Section VI. Finally, the main conclusions of the work are presented in Section VII.

\section{AGgRegation AND ScHEDULING}

In this section, the aggregation model and scheduling process are demonstrated. Fig. 1 illustrates the concepts of the 
presented model. In fact, the model contains two main parts, which are demand side and grid side, where the aggregator is located as an entity between these two sections. In the demand side, the aggregator deals with the consumers and producers somehow it defines DR programs for the consumers and also generation scheduling for the producers in order to manage consumption and generation of resources. In the grid side, the aggregator negotiates with market operators and other network entities in order to participate in the electricity market bids.

The aggregator model presented in this paper utilizes clustering in order to classify the consumption and generation resources for improving the performance of aggregation and remuneration process. By this way, the output results of the aggregation process is energy scheduling of each group, and the outcomes of remuneration process is energy cost of each group.

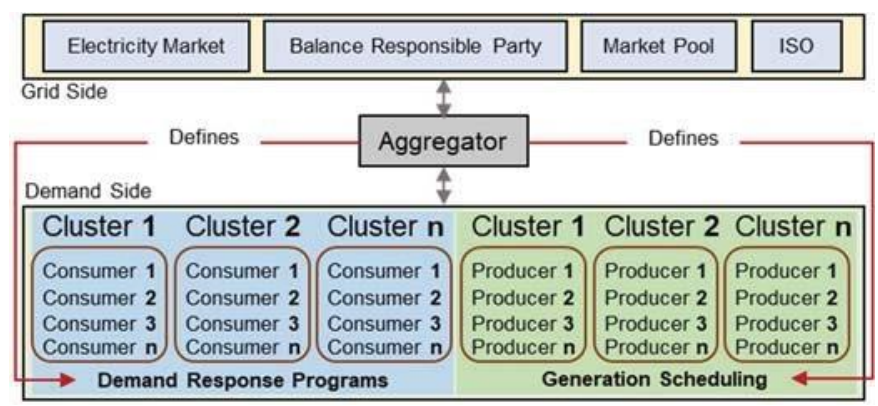

Fig. 1. The overall perspective of the aggregator model.

In this model, aggregator performs the scheduling based on DG units particularly renewable resources, DR programs, and external suppliers. There are three types of DR programs considered for aggregator to offer to the clients who tend to establish DR contract:

Direct Load Control (DLC);

Load Reduction (Red.); Load

Shifting.

The load shifting is considered as a free DR program in this model. In fact, load shifting is considered as an effective tool for the aggregator, since he can manage the overall consumption of the network based on his own generation rate in order to avoid purchasing energy from external suppliers with higher prices by shifting consumption from low generation periods to higher ones. Table I demonstrates the information regarding other DR contracts including DLC and

Reduction.

TABLE I.

DR CONTRACTS INFORMATION. ( $\mathrm{M}=$

MANDATORY; $\mathrm{V}=$ VOLUNTARY)

\begin{tabular}{|c|c|c|c|c|}
\hline $\begin{array}{c}\text { DR } \\
\text { Type }\end{array}$ & $\begin{array}{c}\mathrm{M} \\
/\end{array}$ & Remuneration & Activation/Signal & $\begin{array}{c}\text { Measure/ } \\
\text { Contract }\end{array}$ \\
\hline DLC & $\mathrm{M}$ & $\begin{array}{c}\text { Cost } / \mathrm{kWh} \\
\text { reduced }\end{array}$ & $\begin{array}{c}\text { DLC per } \\
\text { equipment }\end{array}$ & $\begin{array}{c}\text { Actual } \mathrm{kWh} \\
\text { reduction }\end{array}$ \\
\hline Red. & $\mathrm{V}$ & $\begin{array}{c}\text { Cost } / \mathrm{kWh} \\
\text { reduced }\end{array}$ & $\begin{array}{c}\text { Reduction } \\
\text { notification }\end{array}$ & $\begin{array}{c}\text { Actual } \mathrm{kWh} \\
\text { reduction }\end{array}$ \\
\hline
\end{tabular}

In DLC contract, the customers give permission to the aggregator to directly control the related devices during DR event. In this contract, the customer gains remuneration according to $\mathrm{kWh}$ reduction. In Red. contract, before the event, the customer will be informed of the amount of reduction since it should be performed by customer manually or through automation infrastructures. If customer agreed to participate, it obtains remuneration during the DR event based on $\mathrm{kWh}$ reduction.

The presented model deliberates a linear cost function for all involved resources including DGs, DR, and external suppliers. Furthermore, a k-Means Clustering algorithm is used by aggregator in order to categorize its resources in several groups. The remuneration procedure is done after this classification since a tariff is specified for each group, which is called Group tariff.

The maximum available cost in each group will be selected as Group tariff and is equal for all resources in that group. This encourages the cheapest resources to participate in the aggregation since the Group tariff is higher than their costs, and the most expensive resources of the group is satisfied since the Group tariff is equal to their initial cost.

The aggregator can use the proposed approach in the electricity market negotiations and present several bids based on the aggregated energy from each group and its Group tariff. In these bids, the Group tariff would be presented as the minimum rate for the bid tariff, therefore, the aggregator can obtain profits or in the worst case, it can earn the costs that spent for the remuneration and other operational costs.

\section{OPTIMIZATION FORMULATION}

The optimization algorithm and its mathematical formulation are presented in this section. The optimization problem used in this paper has been adapted from [15], and only the most applicable information has been mentioned in the present paper. The formulation solves the optimal scheduling of the resources, including DGs, DR programs, and external suppliers. In this model, the aggregator is not accountable for the technical specifications of the grid; it is considered as the responsibility of network operator.

Equation (1) demonstrates the objective function of the optimization algorithm, which aims to minimize the Total Cost (TC) of the aggregator. There are several constraints formulated and considered for this objective function. Equation (2) presents that in every single period of optimization, load balance is respected, where Ptotal is the total

consumption of the aggregator 


$$
\begin{aligned}
& \text { Minimize } \\
& T C=\sum_{t=1}^{T}\left[\sum_{p=1}^{P} P_{D G(p, t)} \times C_{D G(p, t)}\right. \\
& +\sum_{d=1}^{D}\left[P_{D L C(d, t)} \times C_{D L C(d, t)}\right. \\
& +P_{\text {Red }(d, t)} \times C_{\text {Red }(d, t)} \\
& \left.+\sum_{s=1}^{T} P_{\text {Shift }(d, t, s)} \times C_{\text {Shift }(d, t, s)}\right] \\
& \left.+\sum_{e=1}^{E} P_{E x t(e, t)} \times C_{E x t(e, t)}\right] \\
& \sum_{p=1}^{P} P_{D G(p, t)}+\sum_{e=1}^{E} P_{E x t(e, t)} \\
& +\sum_{\substack{T=1 \\
T}}^{D}\left[P_{D L C(d, t)}+P_{R e d(d, t)}\right. \\
& +\sum_{s=1}^{T}\left(P_{\text {Shift }(d, t, s)}-P_{\text {Shift }(d, s, t)}\right] \\
& =P_{\text {total }(t)} ; \forall t \in\{1, \ldots, T\}
\end{aligned}
$$

(2)

Moreover, (3) and (4) are the technical limitations regarding DG units and external suppliers, and (5) to (8) represent the limitation for DR programs including DLC, Red., and load shifting.

$$
\begin{gathered}
0 \leq P_{D G(p, t)} \leq P_{D G(p, t)}^{M A X} \\
\forall p \in\{1, \ldots, P\} ; \forall t \in\{1, \ldots, T\} \\
P_{E x t(e, t)}^{M I N} P_{E x t(e, t)} \leq P_{E x t(e, t)}^{M A X} \\
\forall e \in\{1, \ldots, E\} ; \forall t \in\{1, \ldots, T\} \\
0 \leq P_{D L C(d, t)} \leq P_{D L C(d, t)}^{M A X} \\
\forall d \in\{1, \ldots, D\} ; \forall t \in\{1, \ldots, T\} \\
0 \leq P_{\text {Red }(d, t)} \leq P_{\text {Red }(d, t)}^{M A X} \\
\forall d \in\{1, \ldots, D\} ; \forall t \in\{1, \ldots, T\} \\
P_{D L C(d, t)}=P_{D L C(d, t)}^{M A X} \times B_{D L C(d, t)} \\
B_{D L C(d, t)} \in\{0,1\} \\
\forall d \in\{1, \ldots, D\} ; \forall t \in\{1, \ldots, T\} \\
\left.P_{\text {Shift }(d, t, s)}^{M I N} P_{\text {Shift }(d, t, s)} \leq P_{\text {Shift }(d, t, s)}^{M A}, T\right\} \\
\forall d \in\{1, \ldots, D\} ; \forall t \in\{1, \ldots, T\} ; \forall s \in\{1, \ldots, T\}
\end{gathered}
$$

In this section, the mathematical formulation regarding the optimization algorithm was demonstrated. In the case study of the paper, the proposed algorithm is utilized by aggregator for scheduling of resources in order to have optimal use of resources.

\section{IMPLEMENTED SCADA SYSTEM}

This section focuses on the automation infrastructures and implemented SCADA system in an office building. The building is in GECAD research center, in ISEP/IPP, Porto, Portugal, where the implemented SCADA system controls and manages a part of the building. In fact, this office building is considered as a customer in the aggregator network, which has the required intelligence in term of controlling and managing the electricity consumption for participating in DR events.

Therefore, it is considered that this customer establishes a contract with the aggregator for DR events and its DG unit. This unit will participate in the aggregation and scheduling processes performed by the aggregator. Fig. 2 illustrates the main controller panel of the implemented SCADA system and

(1) the designed webpage for monitoring and control. This system is responsible for various functionalities, such as monitoring environmental parameters of each office, controlling and checking the door status of each office, the presence detection of each office users, etc., which are not in the scope of this paper. This section focuses on the implemented methodologies for controlling and monitoring the consumption and generation of the building.

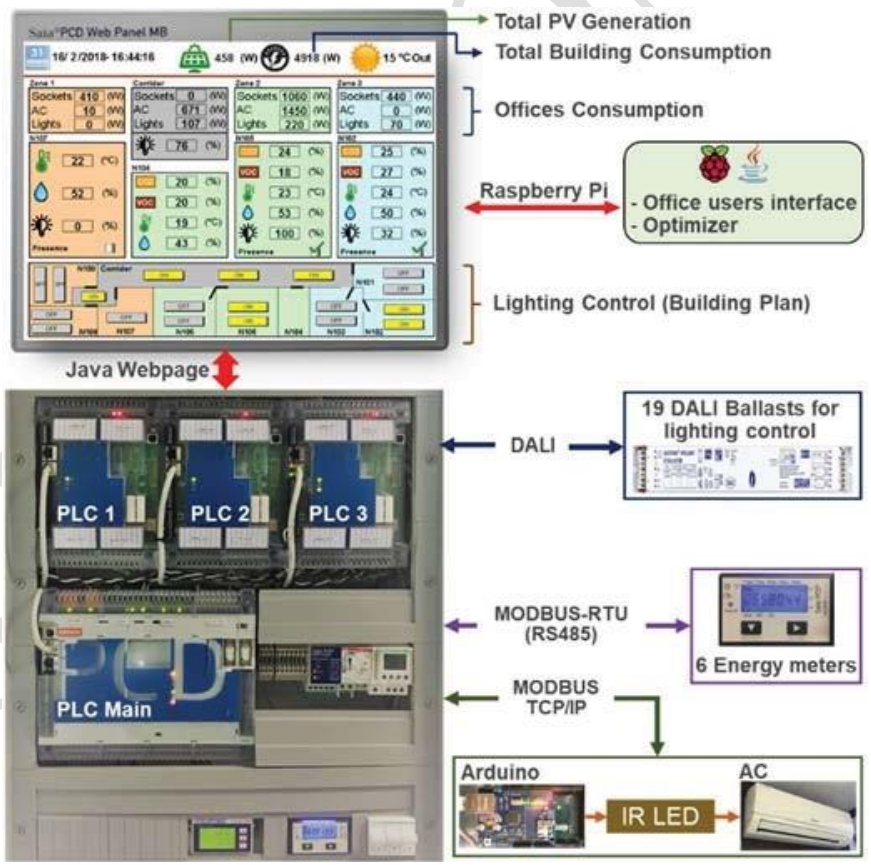

Fig. 2. Implemented SCADA system for the office building.

In this SCADA system, three distributed PLCs, and one Main PLC (as shown in Fig. 2) are used. All PLCs in this system continuously exchange messages with each other for sharing their latest information through TCP/IP communication. Each distributed PLC is responsible for three offices. Therefore, all nine offices of the building are controlled by three distributed based PLCs. This enables the SCADA system to perform decision making locally and communicate with other PLCs to fulfill the overall system's purpose. The Main PLC has two main functionalities: The first one is to acquire the data from other distributed based PLCs and store it in a database; and the second responsibility is to provide a webpage (as illustrated in Fig. 2), which is displayed in a touch screen console for real-time monitoring and controlling. The lighting system of the building includes 19 fluorescent lamps, and for managing these lamps, Digital Addressable Lighting Interface (DALI) is used between 19 DALI ballasts and the related distributed based PLC. By this way, the SCADA fully controls each light individually in order to reduce the consumption. There are 10 Air Conditioning (AC) devices in the building, one in each office and one in the 
main corridor. An Arduino® (www.arduino.cc) equipped with an Ethernet Shield and an Infrared LightEmitting Diode (IR LED) have been programmed and installed near to each AC. Actually, this controlling scenario emulates the remote control of ACs. In other words, the SCADA takes decision for each $\mathrm{AC}$ and transmits the desired command to each $\mathrm{AC}$ controller (Arduino®) via Ethernet interface, and then, Arduino controls the AC based on the SCADA decision (turning OFF/ON). The electricity network of the building is three-phase; the first phase supplies electricity sockets, the second phase supplies ACs, and the third phase supplies lighting system. There are six energy meters in the building; five of them measure the electricity consumption of the building and the other one measures the real-time generation of DG unit (the installed rooftop PV system of the building). All these energy meters transmit data to the related PLC through MODBUS-RTU (RS485) protocol. There is a Raspberry Pi (www.raspberrypi.org) connected to this SCADA, which is responsible to optimize the lights and ACs consumption based on the priorities defined by each office user in a web-based platform. Therefore, whenever the aggregator takes the decision to reduce the building consumption, it transmits a command to the Raspberry $\mathrm{Pi}$, and then, it performs a prioritybased optimization in order to reduce and optimize the consumption of building with respect to user comfort. More details regarding the proposed optimization algorithm of this SCADA is available on [16].

\section{CASE STUdy}

A case study is demonstrated in this section in order to test and validate the capabilities of the proposed models during aggregation and scheduling processes. A low voltage distribution network adapted from [17] is considered for the aggregator. This network has underground electrical lines with 21 buses, where one of the buses is the real location of GECAD office building equipped with SCADA system. In this case study, it is considered that the aggregator network consists of 26 producers and 20 consumers. The producers are $20 \mathrm{PV}$ units, and 4 wind turbines, 1 biomass generator, and 1 external supplier. Furthermore, the consumers include 9 Residential Buildings, 2 Office Buildings, 4 Commercial Shops, 3 Shopping Centers, and 2 Industrial Factories. This classification of consumers is done based on the average of their daily consumption, and GECAD building is considered as one of the office buildings of the aggregator network. Fig. 3 illustrates the consumption and generation profiles considered for the aggregator network during 24 hours, with 96 periods of 15 minutes. As it can be seen in Fig. 3 - (a), Industrial Factories and Shopping Centers have a great contribution to the consumption profile, which a peak period starts from 09:00 to 21:00. Furthermore, as it is clear in Fig. 3-(b), the renewable resources are considered as the main suppliers of aggregator. However, biomass generation with a maximum capacity of 30 $\mathrm{kW}$, and external supplier with a maximum capacity of $300 \mathrm{~kW}$ considered as resources that are always available with their maximum capacity during all periods. In the periods that there is not adequate amount of generation by renewable resources, the aggregator can rely on the biomass and external supplier or perform DR programs to reduce the consumption and keep the network balance. All generation resources, excluding external supplier, can participate in the aggregation for market negotiations. This is obvious during the periods that aggregator has generation surplus, and therefore, not only it can supply all demands of the network, but also it can participate in the market negotiations and gain profits.

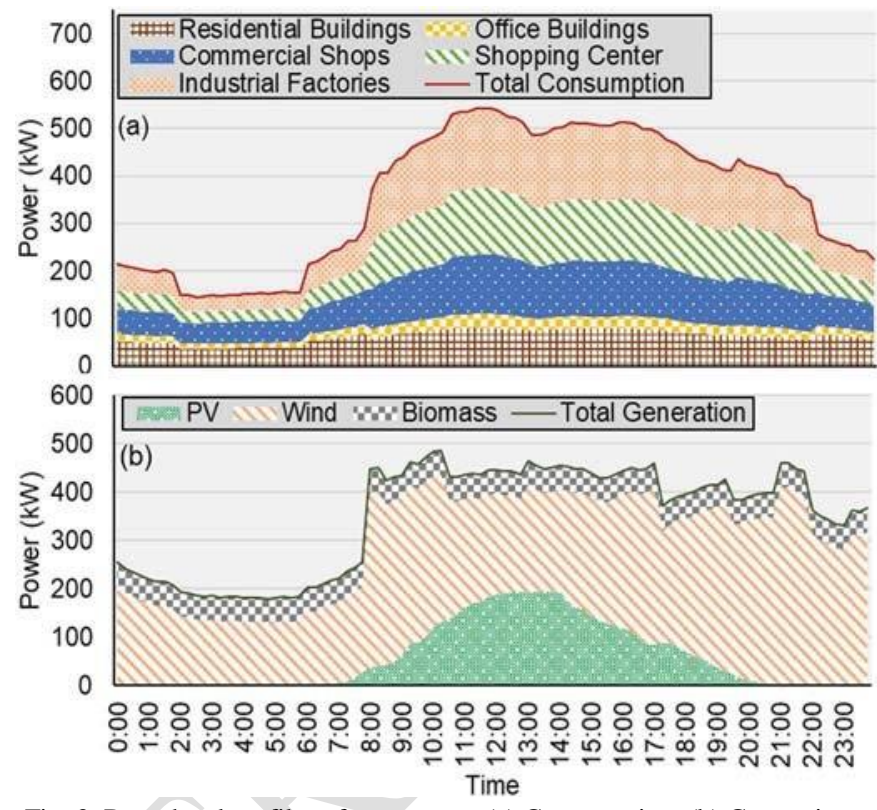

Fig. 3. Day-ahead profiles of aggregator: (a) Consumption; (b) Generation.

The individual price of each energy resource is shown in Table II. These prices are constant during all periods of the case study. The energy cost considered for the external supplier is 0.12 monetary unit per $\mathrm{kWh}$ (m.u./kWh), which is based on the Portuguese section of Iberian Electricity Markets (www.omie.es). In fact, this is the price that aggregator should pay for the purchased energy from external supplier.

\begin{tabular}{|l|c|l|c|}
\hline \multicolumn{1}{|c|}{ TABLE II. } & \multicolumn{1}{c|}{ INDIVIDUAL COSTS FOR ENERGY RESOURCES } \\
\hline PV 1 & $\begin{array}{c}\text { Cost } \\
\text { (m.u./kWh })\end{array}$ & \multicolumn{1}{|c|}{ Resource } & $\begin{array}{c}\text { Cost } \\
\text { (m.u./kWh })\end{array}$ \\
\hline PV 2, 3 & 0.07 & PV 14, 15 & 0.03 \\
\hline PV 4 & 0.05 & PV 16 & 0.08 \\
\hline PV 5 & 0.02 & PV 17 & 0.03 \\
\hline PV 6, 7, 8 & 0.03 & PV 18, 19 & 0.02 \\
\hline PV 9, 10 & 0.08 & Wind 1 & 0.04 \\
\hline PV 11 & 0.06 & Wind 2, 3 & 0.04 \\
\hline PV 12 & 0.05 & Wind 4 & 0.06 \\
\hline PV 13 & 0.02 & Biomass & 0.09 \\
\hline
\end{tabular}

Regarding the DR resources, it is considered that the consumers participating in these programs establish a contract with the aggregator. $20 \%$ of their initial consumption dedicated for DLC and load shifting, and 15\% devoted for Reduction (Red) programs. As it was mentioned, load shifting is considered as a free program in this paper, however, the linear costs considered for customers in the scope of DLC and Red programs are illustrated in Fig. 4. These prices are based on the type of consumers. 


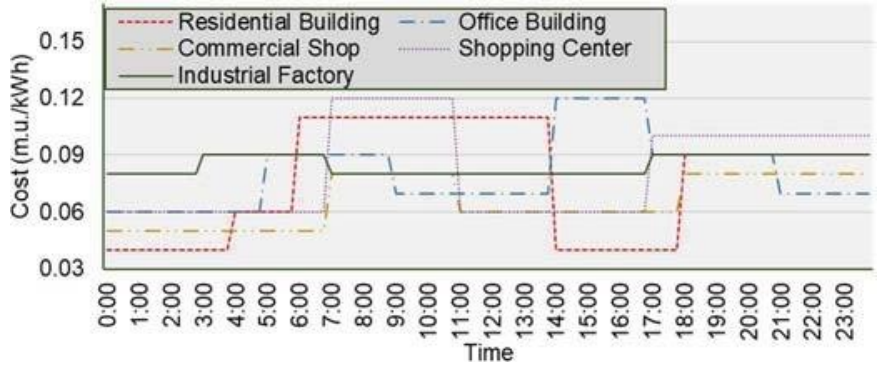

Fig. 4. Linear DR costs considered for both DLC and Red programs.

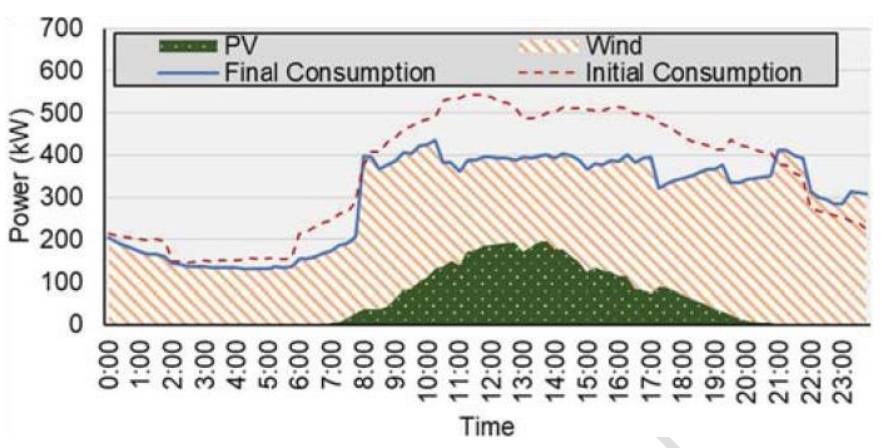

Time

As it was mentioned before, GECAD office building is considered as a customer of the aggregator. For this purpose, a Fig. 6. Aggregator scheduling results for 24 hours. real consumption and generation profile of GECAD building

In fact, the difference between the initial and final is considered for the day-ahead. These profiles are measured consumption in Fig. 6 is the amount of reduction that is done by the
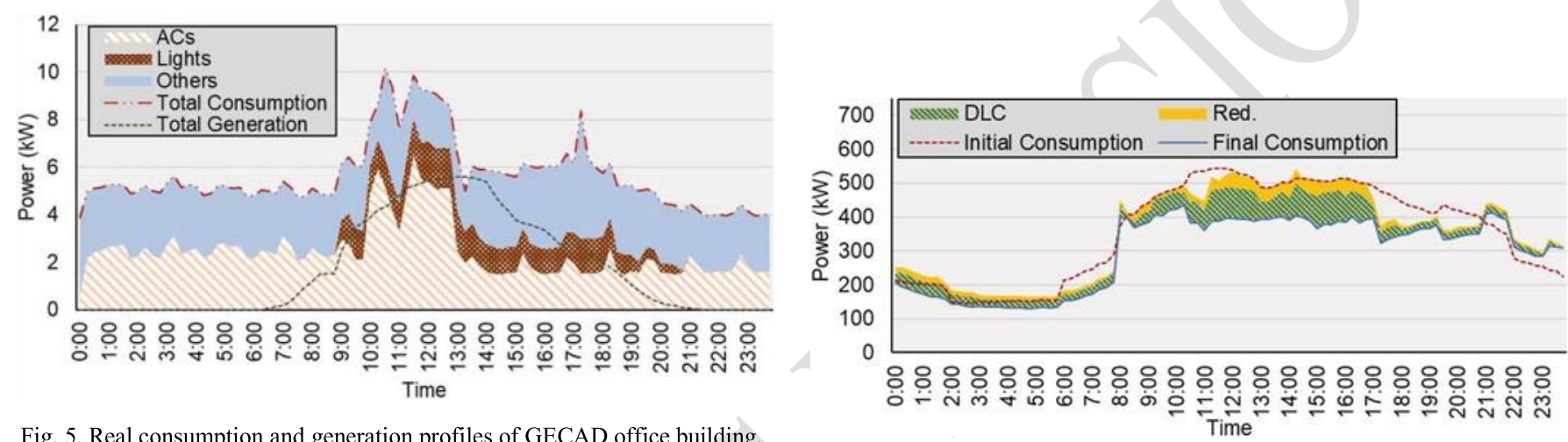

Fig. 5. Real consumption and generation profiles of GECAD office building.
SCADA system and are demonstrated in Fig. 5. through DR programs, including DLC, Red, and load shifting. The detailed information regarding the applied DR programs is shown in Fig. 7.

As Fig. 5 shows, the consumption of the building is divided into the three parts: ACs, lights, and other devices, where the peak of consumption begins in the working hours between 9:00 to 19:00. ACs and lights are the devices that are controlled by the SCADA system in order to participate in DR events. The Others consumption shown in Fig. 5 belongs to the part of consumption that is out of control of SCADA system. Similar to the other customers of aggregator, this particular customer also participates in the aggregation and scheduling, by providing its maximum PV generation as well as participating in the DR events. In this case study, it is considered that AC devices are dedicated to DLC programs and load shifting, and lighting system is available for Red programs.

\section{RESULTS}

In this section, the results of the provided case study are represented. The aggregation and resource scheduling process applied in the case study is solved through TOMLAB (www.tompot.com) tool of MATLAB ${ }^{\mathrm{TM}}$. Fig. 6 illustrates the scheduling results of the optimization problem utilized by the aggregator. As it is clear in Fig. 6, the aggregator reduced the consumption of network till all available renewable resources are able to supply the demand. This would be done by applying DR programs to the electricity consumers. In fact, aggregator tends to employ renewable resources first, since they are cheapest resources in the network, and then, if they are not adequate for the demand, aggregator utilizes biomass or external supplier. However, in this case study, renewable resources were adequate for the demand.

Fig. 7. DR programs applied by the aggregator to its consumers.

As it can be seen in Fig. 7, there are some periods in which the final consumption profile is greater than initial profiles. This is due to the load shifting that aggregator utilized to balance the network. In other words, aggregator employed load shifting to shift the consumption from lower generation moments to the high generation periods in order to avoid purchasing energy from the external supplier or utilizing biomass. The contribution 
of SCADA system in GECAD office building during the scheduling is shown in Fig. 8. Similar to Fig. 7, the difference between the initial and scheduled consumption profiles in Fig. 8 , is the amount of reduction performed by DLC, Red., and load shifting programs. In this particular customer, while the SCADA system obliged by the aggregator to perform Red. DR program, it reduces the lighting system till $15 \%$ of the initial consumption, and in the periods that DLC program is required, aggregator controls the AC devices through the SCADA system. The scheduling results of aggregator for its resources in period number 44 (11:00 AM) is demonstrated in Fig. 9. As it is seen in Fig. 9-(a), the total consumption of aggregator in period number 44 (11:00 AM) was supplied by $26 \%$ PV generation, $42 \%$ wind generation, $11 \%$ DLC reduction, 5\% Red. DR program and $16 \%$ is the shifted load from this period to other periods. Also, as Fig. 9-(b) illustrates, the total consumption of GECAD building was supplied by $71 \%$ internal PV generation, $19 \%$ reduction in AC devices based on DLC, and $10 \%$ reduction in the lighting system in the scope of Red. program. However, if the load flexibility of GECAD building is excluded from the aggregator scheduling, the total consumption of the network in period number 44 (11:00 AM) would be $537.23 \mathrm{~kW}$. This means GECAD load flexibility provides $1.96 \mathrm{~kW}$ reduction in the overall consumption of the aggregator.

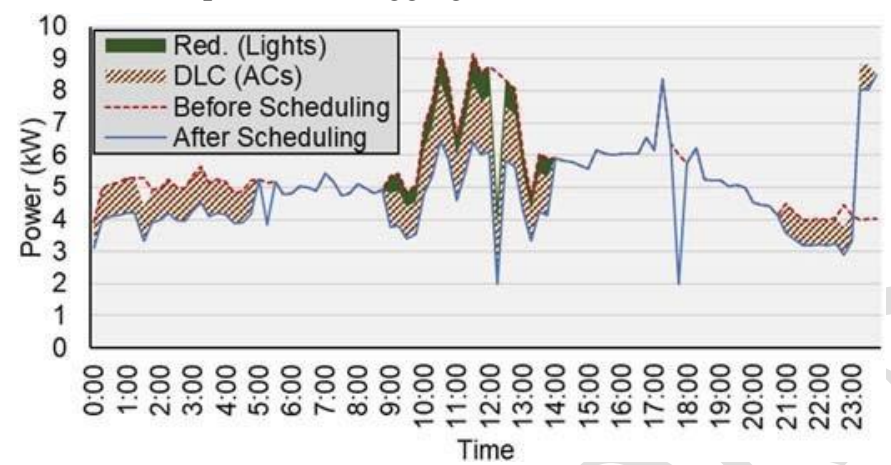

Fig. 8. Consumption scheduling of GECAD building by the aggregator.

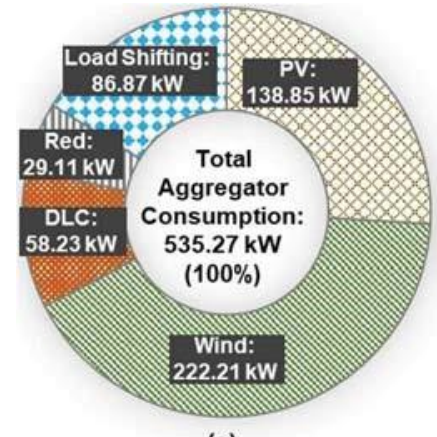

(a)



(b) $\triangle P V \quad \triangle W i n d \approx D L C$ aRed. $₫$ Load Shifting OUT

Fig. 9. Scheduling results for a single period: (a) Entire aggregator (b) GECAD office building.

\section{CONCLUSIONS}

An aggregation model including optimization tools for optimal resource scheduling and aggregating was proposed in this paper. The optimization algorithm utilized by aggregator aimed to minimize the total operational costs by considering renewable energy resources and demand response programs. Furthermore, a real automation model for an office building was presented in order to enable the building to take decisions and participate in demand response events. In the case study, a network with 20 consumers and 26 distributed generations was dedicated to the aggregator. The proposed office building was considered as a customer of aggregator, which established a contract with the aggregator for scheduling and aggregation. The results of case study proved the performance of aggregation model and SCADA office building during aggregating and scheduling. Also, the behaviors of the optimization-based aggregator model to a single intelligent customer have been surveyed.

\section{ACKNOWLEDGEMENTS}

This work has received funding from the Projects: NetEffiCity (ANI|P2020 18015); FEDER Funds through COMPETE program; National Funds through FCT under project UID/EEA/00760/2013; H2020 DREAM-GO Project

(Marie Sklodowska-Curie grant agreement No 641794).

\section{REFERENCES}

[1] A. Srivastava, S. Van Passel and E. Laes, "Assessing the success of electricity demand response programs: A meta-analysis", Energy Research \& Social Science, vol. 40, pp. 110-117, 2018.

[2] J. Wang, H. Zhong, Z. Ma, Q. Xia and C. Kang, "Review and prospect of integrated demand response in the multi-energy system", Applied Energy, vol. 202, pp. 772-782, 2017.

[3] X. Zhang, G. Hug, J. Kolter and I. Harjunkoski, "Demand Response of Ancillary Service From Industrial Loads Coordinated With Energy Storage", IEEE Transactions on Power Systems, vol. 33, no. 1, pp. 951961 , 2018.

[4] O. Abrishambaf, P. Faria, L. Gomes, J. Spínola, Z. Vale and J. Corchado, "Implementation of a Real-Time Microgrid Simulation Platform Based on Centralized and Distributed Management", Energies, vol. 10, no. 12, p. 806-820, 2017.

[5] E. Martínez Ceseña, N. Good and P. Mancarella, "Electrical network capacity support from demand-side response: Techno-economic assessment of potential business cases for small commercial and residential end-users", Energy Policy, vol. 82, pp. 222-232, 2015.

[6] P. Siano, "Demand response and smart grids-A survey", Renewable and Sustainable Energy Reviews, vol. 30, pp. 461-478, 2014.

[7] W. Pei, Y. Du, W. Deng, K. Sheng, H. Xiao and H. Qu, "Optimal Bidding Strategy and Intramarket Mechanism of Microgrid Aggregator in RealTime Balancing Market", IEEE Transactions on Industrial Informatics, vol. 12, no. 2, pp. 587-596, 2016.

[8] S. Bakr and S. Cranefield, "Using the Shapley Value for Fair Consumer Compensation in Energy Demand Response Programs: Comparing Algorithms", 2015 IEEE International Conference on Data Science and Data Intensive Systems, 2015.

[9] J. Zapata Riveros, K. Bruninx, K. Poncelet and W. D'haeseleer, "Bidding strategies for virtual power plants considering CHPs and intermittent renewables", Energy Conversion and Management, vol. 103, pp. 408-418, 2015.

[10] S. Kakran and S. Chanana, "Smart operations of smart grids integrated with distributed generation: A review", Renewable and Sustainable Energy Reviews, vol. 81, pp. 524-535, 2018.

[11] T. Hansen, R. Roche, S. Suryanarayanan, A. Maciejewski and H. Siegel, "Heuristic Optimization for an Aggregator-Based Resource Allocation in the Smart Grid", IEEE Transactions on Smart Grid, vol. 6, no. 4, pp. 17851794, 2015.

[12] G. Marulanda, J. Valenzuela and H. Salazar, "An assessment of the impact of a demand response program on the Colombian day-ahead electricity market", 2014 IEEE PES Transmission \& Distribution Conference and Exposition - Latin America (PES T\&D-LA), 2014.

[13] C. Li, Y. Chen, F. Luo, Z. Xu and Y. Zheng, "Real-Time Decision Making Model for Thermostatically Controlled Load Aggregators by Natural 
Aggregation Algorithm", 2017 IEEE International Conference on Energy Internet (ICEI), 2017.

[14] Q. Jia, J. Shen, Z. Xu and X. Guan, "Simulation-Based Policy Improvement for Energy Management in Commercial Office

Buildings", IEEE Transactions on Smart Grid, vol. 3, no. 4, pp. 22112223 , 2012.

[15] J. Spinola, P. Faria and Z. Vale, "Model for the integration of distributed energy resources in energy markets by an aggregator", 2017 IEEE Manchester PowerTech, 2017.
[16] P. Faria, A. Pinto, Z. Vale, M. Khorram, F. de Lima Neto and T. Pinto, "Lighting consumption optimization using fish school search algorithm", 2017 IEEE Symposium Series on Computational Intelligence (SSCI), 2017.

[17] M. Silva, F. Fernandes, H. Morais, S. Ramos and Z. Vale, "Hour-ahead energy resource management in university campus microgrid", 2015 IEEE Eindhoven PowerTech, 2015. 